\title{
A comparison of "configural" discrimination problems: Implications for understanding the role of the hippocampal formation in learning and memory
}

\author{
MARIA C. ALVARADO and JERRY W. RUDY \\ University of Colorado, Boulder, Colorado
}

\begin{abstract}
Rats were trained on several discrimination problems that should require a "configural" association solution: (1) three variations of the negative-patterning problem, $\mathrm{A}+, \mathrm{B}+, \mathrm{AB}-,(2)$ a conditional discrimination, $\mathrm{AC}+, \mathrm{B}+, \mathrm{AB}-, \mathrm{C}-$, and (3) an $\mathrm{AC}+, \mathrm{B}+, \mathrm{AB}-$ problem. These problems had similar or identical logical descriptions. Yet, our results suggest that the subtle procedural differences between them influenced the processes that enabled the rats to withhold responding to the nonreinforced $\mathrm{AB}$ - compound. These results might help us understand why damage to the hippocampal formation does not always impair performance on nonlinear discriminations. They do not, however, offer any support for Sutherland and Rudy's (1989) configural association system theory of how the hippocampal formation contributes to learning and memory.
\end{abstract}

The idea that animals construct configural representations of the independent elements of a compound stimulus has been in the literature for over 50 years (Gulliksen \& Wolfle, 1938; Pearce, 1987; Razran, 1965; Rudy \& Wagner, 1975). Recently, the concept of a configural stimulus has become central to several theories about how the hippocampal formation contributes to learning and memory (Gluck \& Myers, 1993; Mishkin \& Petri, 1984; Rudy \& Sutherland, 1992; Schmajuk \& DiCarla, 1992; Sutherland \& Rudy, 1989; Wickelgren, 1979).

For example, in an attempt to account for why damage to the hippocampal formation impairs performance on some but not all tests of learning and memory, Sutherland and Rudy (1989; see also Rudy \& Sutherland, 1992) proposed that the hippocampal formation is critical to the normal functioning of the configural association system but not to that of the simple or elemental association system. The configural association system allows the subject to construct a unique representation of the joint occurrence of the independent elements of a compound stimulus that can gain associative control of behavior. The elemental association system allows each independent element of a compound to gain associative control of behavior. Thus, in the elemental system, the response to a compound stimulus reflects the linear sum of the ex-

This research was supported by NSF Grant BNS-9008251 to J.W.R. and by NIMH Fellowship 1 T32 MH18882-03 to M.C.A. M. C. Alvarado's current address is the Department of Neurobiology and Anatomy, University of Texas School of Medicine, Houston, TX 77225 . Correspondence concerning this article should be addressed to J. W. Rudy, Department of Psychology, CB345, University of Colorado, Boulder, CO 80309-0345 (e-mail: jrudy@clipr.colorado.edu). citatory and inhibitory strengths of its component elements (e.g., Rescorla \& Wagner, 1972; Spence, 1936).

It is not always obvious when an animal's behavior is under the control of the configural representation of compound stimulus, but there is a class of discrimination problems that cannot be solved by an elemental association system and requires a configural association system. For example, in a negative patterning discrimination problem (Rescorla, 1972; Whitlow \& Wagner, 1972; Woodbury, 1943), the subject is rewarded $(+)$ for responding when either stimulus A or stimulus B occurs alone but is not rewarded $(-)$ for responding if $A$ and $B$ are presented in compound $(\mathrm{A}+, \mathrm{B}+, \mathrm{AB}-)$. The solution to the problem requires that the subject respond to $A$ or $\mathrm{B}$ alone and not respond to the $\mathrm{AB}$ compound. An elemental associative system cannot solve this problem because the sum of the excitatory strengths of the elements presented in compound would always be greater than the strengths of the individual elements. So, if only this system was available, an animal would respond more on $\mathrm{AB}$ trials than it would on A or B trials. A configural association system that can construct a unique representation of the joint occurrence of A and B would provide a solution to this problem. Since it is well known that rats, dogs, and rabbits can solve the negative-patterning problem (Rescorla, 1972; Whitlow \& Wagner, 1972; Woodbury, 1943), it is reasonable to assume they have a configural association system.

Because problems such as negative patterning cannot be solved by an elemental system, Sutherland and Rudy (1989) suggested that comparing animals with damage to the hippocampal formation on this class of problems and problems that can be solved by an elemental system would provide an unambiguous test of their theory. Ani- 
mals with damage to the hippocampal formation should solve linear problems that permit an elemental solution but should be impaired on problems that have nonlinear solutions and require a configural system.

In support of configural association theory, there are now several reports that rats with damage to the hippocampal formation are impaired in learning the negativepatterning problem but can solve other elemental problems (Alvarado \& Rudy, 1993; Murphy et al., 1993; Rudy \& Sutherland, 1989; Sutherland, Hill, McDonald, \& Rudy, 1989; but see Davidson, McKernan, \& Jarrard, 1993). Rats with damage to the hippocampal formation trained on the $\mathrm{A}+, \mathrm{B}+, \mathrm{AB}-$ problem respond, as control rats do, to the $A$ and $B$ elements, but they also respond more to the $A B$ compound than control rats.

Yet, as the theory has been tested with other appropriate discrimination learning problems, contrary results have been reported (e.g., Gallagher \& Holland, 1992; Whishaw \& Tomie, 1991). Of particular interest is Gallagher and Holland's (1992) finding that rats with damage to the hippocampal formation are not impaired on a problem that is quite similar to the negative-patterning problem. Their rats were rewarded for responding to an $\mathrm{AC}$ compound and to $\mathrm{B}$ alone but were not rewarded for responding to an $\mathrm{AB}$ compound or to $\mathrm{C}$ alone $(\mathrm{AC}+, \mathrm{B}+$, $A B-, C-)$. The only difference between this problem and negative patterning $(\mathrm{A}+, \mathrm{B}+, \mathrm{AB}-)$ is the introduction of an additional element, $C$, that occurs on trials when $\mathrm{A}$ is reinforced and that also occurs alone.

The negative-patterning problem and the GallagherHolland problem require that the animal has some way to represent to the joint occurrence of the elemental stimuli when they occur in compound. Thus, they cannot be solved by an elemental associative system. Nevertheless, the fact that the two problems are differentially sensitive to damage to the hippocampal formation suggests that the slight procedural differences between the two problems influence the processes through which the $\mathrm{AB}-$ compound controls responding. The experiments we report address this possibility.

\section{EXPERIMENT 1}

Both the Gallagher-Holland $\mathrm{AC}+, \mathrm{B}+, \mathrm{AB}-, \mathrm{C}-$ problem and the negative-patterning problem, $\mathrm{A}+, \mathrm{B}+$, $\mathrm{AB}-$, require the rat to withhold responding to a compound, $A B$, composed of elements $A$ and $B$ that are reinforced when presented outside of the compound. Yet, as Gallagher and Holland (1992) noted, one difference between these two problems is that the A element of the Gallagher-Holland problem is never experienced alone. This difference might influence the processes through which the $\mathrm{AB}-$ compound controls responding.

To assess the importance of this difference, rats were trained initially to solve either a negative-patterning (NP) $\mathrm{A}+, \mathrm{B}+, \mathrm{AB}-, \mathrm{C}-$ that was similar to the GallagherHolland (GH) problem, $\mathrm{AC}+, \mathrm{B}+, \mathrm{AB}-, \mathrm{C}-$, except that $\mathrm{C}$ was not presented in compound with $\mathrm{A}$. In Phase 2, rats in both groups then received three training sessions of only $A+$ trials. Finally, in Phase 3 , all rats were compared on the negative-patterning problem $\mathrm{A}+, \mathrm{B}+$, $\mathrm{AB}-$. If the fact that the $\mathrm{A}$ element was never presented alone and reinforced in the Gallagher-Holland problem is important, then the additional $\mathrm{A}+$ trials might effect subsequent responding to the $\mathrm{AB}$ compound during Phase 3, relative to that for rats trained on the negativepatterning problem.

\section{Method}

\section{Subjects}

The subjects were 11 male Long-Evans hooded rats purchased from Charles River when 40 days old. The rats were group housed, 2 or 3 to a cage, and allowed to acclimate to the colony for 2 weeks. The colony room was maintained on a 12:12-h light:dark cycle.

\section{Apparatus}

Operant discrimination training took place in eight identical operant chambers $(19.5 \times 29 \times 23.5 \mathrm{~cm})$ constructed of clear Plexiglas sides and aluminum front and rear walls. The floor was constructed from 2-mm stainless steel rods, placed $12 \mathrm{~mm}$ apart. Food pellets (Noyes Company, $45 \mathrm{mg}$ ) were dispensed through a small opening on the left side of the front panel, and the lever $(5 \times 5 \mathrm{~cm})$ was located on the right side of the front panel, $4 \mathrm{~cm}$ above the floor and $9 \mathrm{~cm}$ away from the food opening. The chambers were individually housed in sound- and light-attenuating shells $(36 \times 36$ $\times 30 \mathrm{~cm}$ ). Ventilation and masking noise were provided by exhaust fans. Stimulus A was the onset of a $7.5-\mathrm{W}$ bulb that was mounted on the wall of the sound-attenuated chamber so that it was above and to the right of an animal facing the pellet dispenser. Stimulus $B$ was a $2,000-\mathrm{Hz} 80-\mathrm{dB}$ tone, and stimulus $\mathrm{C}$ was a $6-\mathrm{Hz} 80-\mathrm{dB}$ clicker presented through a speaker mounted on the ceiling of the shell. Presentation of stimuli and data recording were controlled by Commodore 64 computers.

\section{Procedure}

Food rationing and preliminary training. Ten days prior to the beginning of training, when the rats weighed about $300 \mathrm{~g}$, they were individually housed and their weight was gradually reduced to $85 \%$ of their free-feeding body weight by restricting their daily food ration to $15 \mathrm{~g}$ per day. The rats then were trained to barpress. After the barpress was established, the rats received 3 days of training on a variable-interval $(30$-sec) reinforcement schedule. Each session lasted $30 \mathrm{~min}$. The rats then received 4 days of training to establish stimulus B as the discrimination stimulus. Each session consisted of 40 trials. A trial began with the onset of $B$. A barpress terminated $B$ and resulted in delivery of a food pellet. If the animal failed to barpress within $15 \mathrm{sec}$ of B's onset, B was terminated. The intertrial interval was $30 \mathrm{sec}$ during the first two session and $45 \mathrm{sec}$ on the last two sessions.

Phase 1: Acquisition. At the completion of preliminary training, the rats were assigned to either Group GH $(n=6)$ or Group NP $(n=5)$. The rats experienced four types of training trial in each session. Rats in Group GH were trained on a problem that had four trial types: $\mathrm{AC}+, \mathrm{B}+, \mathrm{AB}-$ and $\mathrm{C}-$. Rats in Group NP were trained on a negative-patterning problem that also had four trial types: $\mathrm{A}+, \mathrm{B}+, \mathrm{AB}-$, and $\mathrm{C}-$. During the first 22 sessions, there were 15 trials of each type, at which point, training was judged to be proceeding too slowly, and the number of trials of each type was increased to 30 (total of 120 trials). Training occurred for another 18 sessions bringing the total to 42 . On a trial, the stimuli were presented for a maximum of $15 \mathrm{sec}$. The intertrial interval averaged $45 \mathrm{sec}$. The presentation order of stimuli was determined pseudorandomly with the stipulation that within 8 trials, each stimulus was presented twice; the presentation order within that block of 8 trials was random. 
Phases 2 and 3: A + training and testing. At the end of the training period, the rats were given 3 sessions of $A+$ training, 40 trials per session. All rats were then tested for 3 sessions on the negativepatterning problem, $\mathrm{A}+, \mathrm{B}+$, and $\mathrm{AB}-$. During these sessions, there were 30 presentations of each stimulus, and the intertrial interval was $45 \mathrm{sec}$.

Dependent variable. The dependent variable was the number of trials in which the rat responded to each stimulus.

\section{Results}

During acquisition, the rats in the two groups responded equivalently to the stimuli that signaled a reinforced trial. Figure 1 shows that during acquisition the two groups did not differ in responding to the $\mathrm{AB}-$ $(F<1)$. The last session of acquisition is shown in Figure 2 . It shows that the rats in both groups made fewer responses on $\mathrm{AB}-$ and $\mathrm{C}-$ trials than they did on $\mathrm{A}+, \mathrm{B}+$, or $\mathrm{AC}+$ trials and that there were no differences between the groups on the reinforced trials. A two-way repeated measures analysis of variance (ANOVA) revealed a main effect of trial type $[F(3,27)=102.6, p<.001]$, but neither the effect of group nor the group $\times$ trial type interaction was significant. Post hoc analysis indicated that the rats responded less to both nonrewarded stimuli $(\mathrm{C}-$ and $\mathrm{AB}-)$ than they did to the rewarded stimuli $(\mathrm{A}+$ or $\mathrm{AC}+$ and $\mathrm{B}+$ ) and that they responded less to $\mathrm{C}-$ than they did to AB - (Newman-Keuls test, $p<.05$ ).

There were no differences between the two groups during the $\mathrm{A}+$ training phase. The rats in both groups responded to the light on at least 28 out of the 30 trials in each session. During the test sessions, the groups also did not differ on the reinforced trials with the A and B elements. The groups, however, responded differently to the $\mathrm{AB}$ compound. This difference can be seen in. Figure 3 , which presents responding to the $A B$ compound during the last session of acquisition training and during the 3 sessions of transfer testing. Rats in Group NP were unaffected by interspersed sessions of A+ trials. In contrast, rats in Group GH showed a significant increase in responding to the $\mathrm{AB}$ compound during the first test session relative to their performance on the last training

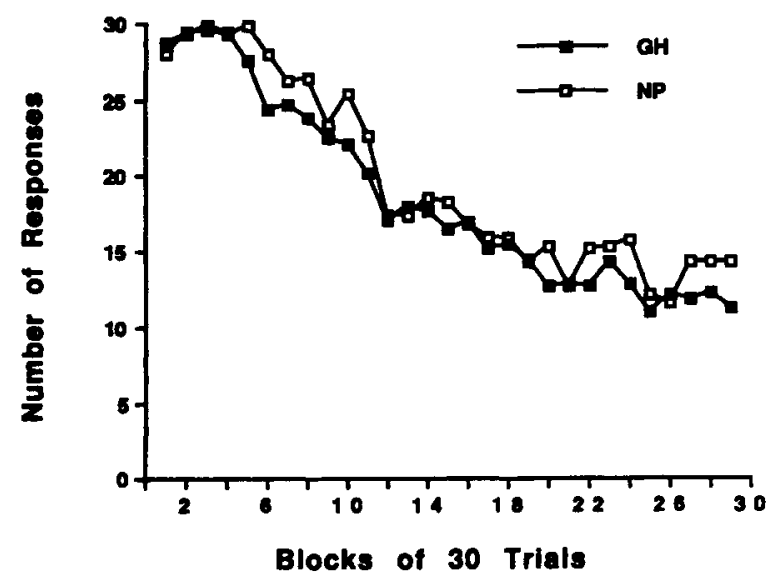

Figure 1. Mean number of responses to the $\mathrm{AB}$ compound during acquisition training.

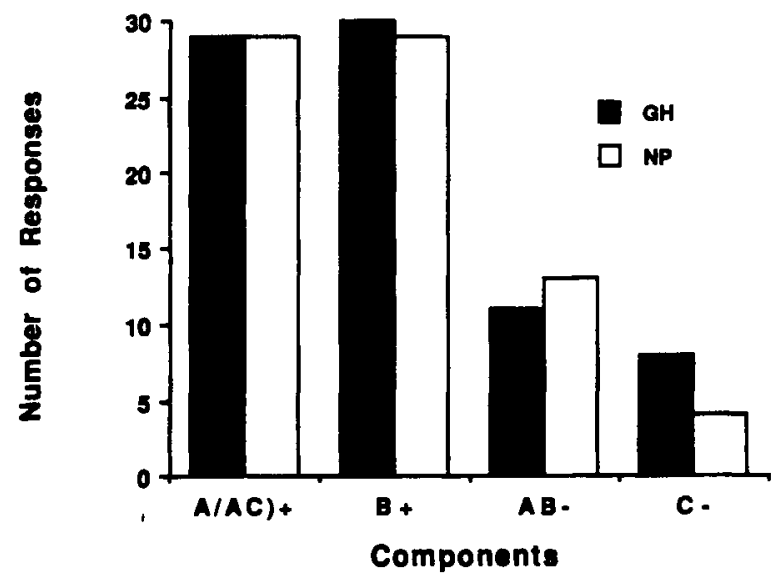

Figure 2. Mean number of responses to the components of the two discrimination problems during the last session of acquisition training.

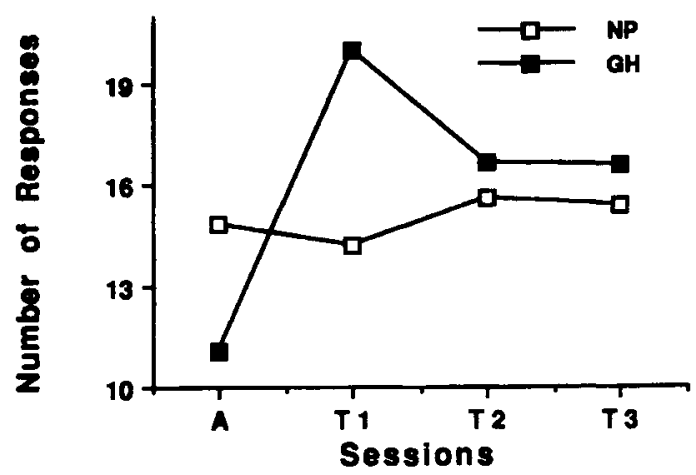

Figure 3. Mean number of responses to the $A B$ compound during the last session of acquisition training and the three test sessions.

session. A group $\times$ sessions ANOVA on these data revealed only a significant interaction $[F(3,27)=3.3, p<$ $.04]$. Neither the group $(F<1)$ nor session $[F(3,27)=$ $2.7, p<.07]$ effect was significant. An analysis of the simple effects indicated that session was significant for Group GH $[F(3,27)=6.3, p<.002]$, but not for Group NP $(F<1)$. In addition, the difference between the two groups approached significance on the first test session $[F(1,18)=3.4, p<.08]$.

\section{Discussion}

While the rats in the two groups did not differ during acquisition, the results of the test revealed differences between them. The rats trained initially on the GallagherHolland problem displayed increased responding to $\mathrm{AB}$ - compound, relative to the rats trained on the negative-patterning problem. This result is likely due to the differential effect that the additional A+ trials had on the two groups of rats. Thus, it appears that the processes through which the $\mathrm{AB}-$ compound controls responding are influenced by the fact that the $A$ element was never presented alone and reinforced in the Gallagher- 
Holland problem but was in the negative-patterning problem. This point will be discussed more fully in the General Discussion.

\section{EXPERIMENT 2}

Although the negative-patterning and GallagherHolland problems have similar logical structures, the results of Experiment 1 indicate that subtle variation in the parameters of the problem can influence the processes whereby the $\mathrm{AB}-$ compound controls responding. The purpose of Experiment 2 was to use the same experimental design to compare other logically similar problems. Consider the basic negative-patterning problem, $\mathrm{A}+, \mathrm{B}+, \mathrm{AB}-$. In Experiment 1, the rats experienced all trial types within each training session. It is possible, however, to implement this discrimination problem in a variety of ways. For example, one could arrange the problem so that $\mathrm{A}+$ trials and $\mathrm{B}+, \mathrm{AB}-$ trials occur in alternate sessions (1) $A+$ and (2) $B+, A B-$; or one could arrange training so that there were four types of sessions (1) $\mathrm{A}+$, (2) $\mathrm{B}+, \mathrm{AB}-$, (3) $\mathrm{B}+$, and (4) $\mathrm{A}+$, $A B-$. Note that the same formal description applies to all three versions of the problem; the rat was rewarded for responding to $\mathrm{A}$ and $\mathrm{B}$ alone but not rewarded for responding to the $\mathrm{AB}$ compound. All problems require the subject to withhold responding to a compound, $A B$, that is composed of elements that signal reward when presented alone. It is possible, however, that presenting the $\mathrm{A}+$ trials, $\mathrm{B}+$ trials, and $\mathrm{AB}$ - trials in different sessions also might influence the processes that enable the $A B-$ compound to control responding.

Consider also the $\mathrm{AC}+, \mathrm{B}+, \mathrm{AB} \rightarrow$ problem studied by Pearce and Wilson (1990). It is quite similar to the negative-patterning problem, $\mathrm{A}+, \mathrm{B}+, \mathrm{AB}-$; however, like the Gallagher-Holland problem, it does not include $\mathrm{A}+$ only trials. Thus, it is likely that this factor also will influence the processes enabling the $\mathrm{AB}$ compound to control responding relative to those for the rats trained on the standard within-session negative-patterning problem.

In Experiment 2, we used the same strategy introduced in Experiment 1. The rats were trained to solve their respective problems, given additional $\mathrm{A}+$ sessions, and then compared on the within-session negative-patterning problem, $\mathrm{A}+, \mathrm{B}+, \mathrm{AB}-$.

\section{Method}

\section{Subjects}

The subjects were 24 male Long-Evans hooded rats purchased from Charles River when 40 days old. The rats were group housed, 2 or 3 to a cage, and allowed to acclimate to the colony for 2 weeks. The colony room was maintained on a 12:12-h light:dark cycle.

\section{Procedure}

The apparatus and preliminary training was the same as described for Experiment 1. Subjects in Group NP $(n=6)$ received three types of training trials within a daily session $(A+, B+$, $\mathrm{AB}-$ ). During a session, there were 40 trials of each type, and the intertrial interval was $45 \mathrm{sec}$. Rats in Group NP:Split $(n=6)$ were trained in the same manner as those in Group NP, except that the three trial types were not experienced on the same day. On alternate days, a session contained only the $\mathrm{A}+$ trials or the $\mathrm{B}+, \mathrm{AB}-$ trials. Across the 2 days, however, this group received the complete set of trials that define negative-patterning discrimination. Subjects in Group NP:Mixed $(n=6)$ also never experienced the three trial types in the same session. They experienced four types of sessions, (1) $\mathrm{A}+$, (2) $\mathrm{B}+, \mathrm{AB}-$, (3) $\mathrm{B}+$, and (4) $\mathrm{A}+, \mathrm{AB}-$. Training was scheduled so that each session type occurred within a block of 4 sessions. Subjects in the Pearce-Wilson condition, Group PW $(n=6)$ experienced three trial types within each session, $\mathrm{AC}+, \mathrm{B}+$, $\mathrm{AB}-$. All rats received 640 presentations of each trial type. Groups NP and PW received these trials over 16 training sessions, whereas Groups NP:Split and NP:Mixed received 32 sessions.

After the completion of training, all subjects received 4 sessions of $40 \mathrm{~A}+$ trials. The next day, all subjects were trained on the within-session negative-patterning problem, $\mathrm{A}+, \mathrm{B}+, \mathrm{AB}-$. Training during these 3 sessions was exactly as described for Group NP.

\section{Results}

Throughout the training and testing, rats in all groups responded equivalently to the stimuli that signaled a reinforced trial, A, B, or AC. Averaged over the last 2 training sessions, Group NP averaged 39 and 38 responses to the A and B elements, Group NP: Split averaged 39.5 and 39.7, Group NP:Mixed averaged 38.5 and 37.4, and Group PW averaged 38.6 to $\mathrm{AC}$ and 39 to $\mathrm{B}$. There was no effect of group $[F(3,20)=1.06, p<.38]$ or stimulus $(F<1)$, and no interaction $[F(3,20)=1.03, p<.35]$. Thus, to simplify the data presentation and analysis, we will focus only on responding to the critical $A B$ compound. As shown in Figure 4, rats in all groups learned to withhold responding to the $\mathrm{AB}$ compound, but there were significant differences among the four groups. By the end of training, rats in Groups NP:Split and PW responded significantly less than did rats in Groups NP and NP:Mixed. An ANOVA on the data for the last 5 training sessions revealed a significant effect of group $[F(3,20)=7.02, p<.002]$, but no effect of sessions $[F(4,80)=2.1, p=.08]$ and no group $\times$ session interaction $[F(12,80)=1.5, p<.13]$. Post hoc comparisons indicated that Groups NP:Split and PW differed (NewmanKeuls test, $p<.05$ ) from NP and NP:Mixed. No other comparisons approached statistical significance.

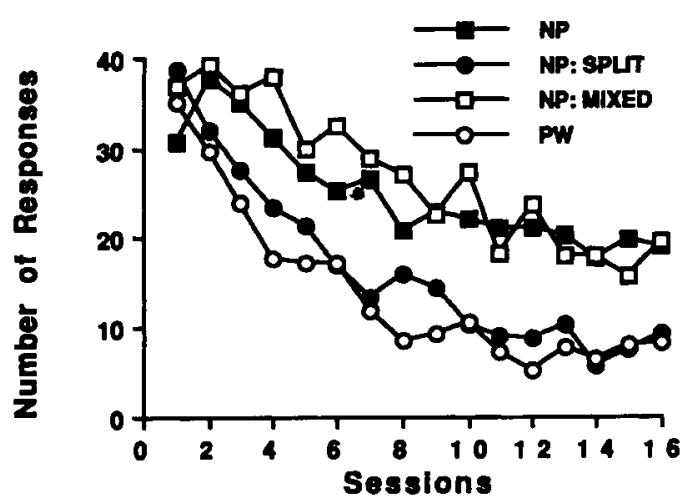

Figure 4. Mean number of responses to the $\mathrm{AB}$ compound during acquisition training. 
During the 4 sessions in which all rats received only $\mathrm{A}+$ training, there were no differences among the groups. The mean number of responses during the first session was 38, 39, 39, and 35 for Groups NP, NP:Split, NP: Mixed, and PW, respectively; during the final session, the mean was 39 for each group. During the test phase, the four groups also did not differ on the $\mathrm{A}+$ and $\mathrm{B}+$ trials. However, as shown in Figure 4, during the testing, rats in Groups NP:Split and PW dramatically increased their responding to the nonreinforced $\mathrm{AB}$ compound relative to their responding during the last session of acquisition training. In contrast, rats in Group NP responded at the same level during test sessions as they did during training, and rats in Group NP:Mixed decreased their responding somewhat during the test sessions. An ANOVA on these data found no effect of group, but the effect of session $[F(3,60)=10.2, p<.001]$ and the group $\times$ sessions interaction $[F(9,60)=7.4, p<.001]$ were both significant. An analysis of the simple effects indicated a significant effect of session for group NP:Split $(p<.001)$, Group PW $(p<.001)$, and Group NP:Mixed $(p<.02)$.

Rats in Groups NP, NP:Split, and NP:Mixed were trained on the same negative-patterning problem, except that the manner in which the components were experienced varied across sessions. Nevertheless, Figure 5 suggests that rats in Group NP:Split not only responded less during acquisition training than did rats in Groups NP and NP:Mixed but also responded more during the test sessions. An ANOVA on the three NP groups assessed whether the procedural differences between the groups affected performance on negative patterning. This analysis yielded a significant group $\times$ session interaction $[F(6,45)$ $=9.6, p<.001]$. Analysis of the simple main effects confirmed differences among the groups during the last session of acquisition $(p<.05)$ and during Test Sessions 2 and $3(p<.03)$. Post hoc comparison indicated that Group NP:Split differed from Groups NP and NP:Mixed during each of these sessions (Newman-Keuls test, $p<.05$ ).

\section{Discussion}

The rats were trained on problems with either identical or very similar logical descriptions. Yet, as was the

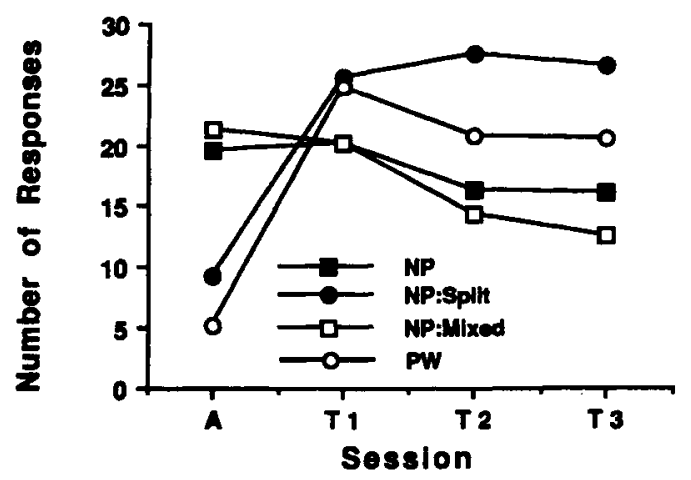

Figure 5. Mean number of responses to the $\mathrm{AB}$ compound during the last session of acquisition and the three test sessions. case in Experiment 1, the slight procedural differences between the problems influenced the processes that enabled the $\mathrm{AB}$ - compound to control responding. During acquisition training, rats in Groups NP:Split and PW made fewer responses to the $\mathrm{AB}$ - compound than did rats in Groups NP and NP:Mixed. Moreover, following additional A+ trials, rats in Groups NP:Split and PW significantly increased responding on $\mathrm{AB}$ - trials of the test relative to their level of responding at the end of training, whereas the performance of Groups NP and NP:Mixed did not change.

\section{GENERAL DISCUSSION}

Recent tests of Sutherland and Rudy's (1989) theory, using very similar but not identical nonspatial discrimination procedures, have yielded contradictory results (see Introduction). This set of experiments was designed to provide some insight into why performance on some problems, such as within-session negative patterning, are influenced by hippocampal formation damage and other problems, such as the Gallagher-Holland problem, are not. We compared rats that were trained on very similar problems.

The results of these experiments indicated that, in spite of the formal similarity of these problems, the procedural differences between them influenced the processes that enabled the rats to withhold responding to the nonreinforced $\mathrm{AB}$ compound. This was reflected both in how the rats responded to the $\mathrm{AB}$ compound during acquisition (rats in Groups NP:Split and PW responded less to $A B$ than did rats in Groups NP and NP:Mixed) and in how they responded to the $\mathrm{AB}$ compound following the additional sessions of $A+$ trials (rats in Groups $\mathrm{GH}, \mathrm{NP}:$ Split, and $\mathrm{PW}$ increased responding to $\mathrm{AB}$, whereas rats in Group NP and NP:Mixed did not).

One approach to this data set might be to argue that rats are using qualitatively different strategies to solve these problems. For example, the rats used a configural solution to solve the within-session negative-patterning problem (that is sensitive to damage to the hippocampal formation) but used some other, nonconfigural strategy to solve the Gallagher-Holland problem (that is not sensitive to damage to the hippocampal formation).

This approach is, however, unjustified for at least two reasons. First, to offer a two-solution interpretation of these data requires that we specify exactly what the alternative nonconfigural strategy is. Others may be able to do so, but we cannot. We see no way to explain this data set without assuming that the animals use configural learning processes to solve all the problems we studied here, with the possible exception of the Pearce-Wilson problem. Second, it appears possible to give a reasonable account of the entire data set with Pearce's (1987) configural theory of conditioning. This approach assumes that the differences between the groups reflect how the different training procedures influenced the processes through which the $\mathrm{AB}$ - compound controls behavior. Before de- 
tailing the application of Pearce's theory to the data, however, it is appropriate to acknowledge the possibility that these groups differ for some other reason. For example, during training, the $\mathrm{AB}$ - compound might have had the same control over responding in all groups. During the test phase, however, the unexpected combination of $\mathrm{A}+$ and $\mathrm{AB}$ - trials in the same session might have disrupted responding to the $\mathrm{AB}$ - compound by Groups $\mathrm{GH}$, PW, and NP:Split. Note, however, this hypothesis would not account for why Groups NP:Split and PW responded less on $\mathrm{AB}$ - trials during training than did Groups NP and NP:Mixed. Thus, we turn to Pearce's theory.

Pearce (1987) assumes that animals treat all discriminative stimuli as inherently configural. As a consequence of a conditioning trial, depending on its outcome, the aggregation of cues (the configural unit) present will acquire either excitatory or inhibitory strength. So, in negative patterning $(\mathrm{A}+, \mathrm{B}+, \mathrm{AB}-), \mathrm{A}$ and $\mathrm{B}$ acquire excitatory strength and the $\mathrm{AB}$ configuration acquires inhibition. Responding to $A B$ is determined by the inhibition it controls and the excitation that generalizes to it from $A$ and $B$. Over the course of acquisition, the $A B$ unit is assumed to acquire sufficient inhibitory strength to suppress the generalized excitation that results to it from $A$ and $B$.

Pearce's model predicts that additional $\mathrm{A}+$ training should differentially impact on the various training procedures used in the present experiments because it differentially adds a new source of excitatory strength that will generalize to influence performance to the $A B$ compound. For example, after completion of the GallagherHolland procedure $(\mathrm{AC}+\mathrm{B}+, \mathrm{AB}-, \mathrm{C}-)$, inhibition acquired by $A B$ should offset excitation generalizing to it from $\mathrm{AC}$ and $\mathrm{B}$. However, additional $\mathrm{A}+$ training should add a third source of excitation that would generalize to $\mathrm{AB}$ and that would result in increased responding to $\mathrm{AB}$. The same analysis applies to the Pearce-Wilson procedure $(\mathrm{AC}+, \mathrm{B}+, \mathrm{AB}-)$. Additional training to $\mathrm{A}+$, however, should not affect subsequent performance after training on the within-session negative-patterning $(\mathrm{A}+$, $\mathrm{B}+, \mathrm{AB}-$ ) procedure, because A's excitatory strength should already be at asymptote.

Pearce's model has more difficulty in explaining why the subjects trained on the three versions of the negativepatterning problem performed differently during the test phase. Without additional assumptions, it would have to predict that there would be no differences among the groups. Yet, rats trained on the NP:Split problem $(\mathrm{A}+\mathrm{B}+, \mathrm{AB}-)$ responded significantly more to the $\mathrm{AB}$ compound than did those trained on the within-session negative-patterning problem or the NP:Mixed problem.

In the context of Pearce's model, however, one might assume that because $\mathrm{A}+$ trials never occur in the $\mathrm{B}+$, $\mathrm{AB}$ - session, there was less generalized excitation from $\mathrm{A}$ on $\mathrm{AB}-$ trials. Two consequences follow from this assumption: (1) During training, subjects in Group NP: Split should respond less on $A B$ trials than should those in Group NP. This was in fact observed. (2) The AB unit for Group NP:Split would acquire less inhibition than it would for Group NP. This would mean that, following additional $\mathrm{A}+$ trials, when the subjects were then tested on all elements of the problem within the session, there would be more generalized excitation from $A$ to $A B$ than could be suppressed by the inhibitory properties associated with the $A B$ unit. Consequently, rats in Group NP:Split should respond more on $A B$ - trials than should rats in Group NP. This result also was observed.

Thus, with the reasonable assumption that elements generalize more to the compound when they are experienced in the same session than when experienced between sessions, Pearce's model can explain the differences between Group NP:Split and NP. This assumption also might enable Pearce's model to explain why Group NP:Mixed did not differ from Group NP during the test. These animals also never experienced $\mathrm{A}+, \mathrm{B}+$, and $\mathrm{AB}$ - trials in the same session. However, they did experience each element in sessions that included $\mathrm{AB}$ - trials. If one assumed that this procedure increased the level of generalized excitation from the elements to the compound, then one would expect that subjects in this group would behave like those in Group NP.

That discrimination problems with similar or identical logical structures can lead to different behavioral outcomes raises the possibility that one may ultimately be able to explain the contradictory results that have been observed when the effects of hippocampal formation damage on nonlinear discrimination problems have been assessed. This fact, however, does not provide any support for Sutherland and Rudy's configural association theory. As noted, we see no way of accounting for the pattern of behavioral results without assuming that all of the problems require the animal to use configural associations. Moreover, as discussed, Pearce's configural theory provides a reasonable account of the whole data set. As such, Sutherland and Rudy's theory still has to predict that damage to the hippocampal formation will impair performance on all the problems (with the exception of the Pearce-Wilson problem), and this prediction is wrong.

Damage to the hippocampal formation, however, does impair performance on some nonlinear discrimination problems. Thus, the challenge is to specify what properties of nonlinear discriminations determine when the hippocampal formation will and will not be essential for a solution to the problem. Taking a clue from the analysis of the data from Pearce's theory, one might speculate that hippocampal formation involvement depends on the degree to which the elements of a compound (e.g., A and B) provide sources of generalized excitation that oppose the inhibitory control conditioned to a configural unit (AB). When combined generalization is strong, such as in within-session negative patterning, the hippocampal formation will contribute importantly to the solution. When combined generalization is relatively weak, such as in the case of the Gallagher-Holland problem, it will not. This analysis also would predict that the hippocampal formation plays an essential role in enabling rats to solve the NP:Mixed problem but not the NP:Split 
problem. If this analysis is correct, one might infer that the hippocampal formation contributes to the solution of some nonlinear discriminations by reducing excitatory generalization from the elements to the compound.

\section{REFERENCES}

Alvarado, M., \& Rudy, J. W. (1993). Configural theory and the hippocampus: Is lesion type critical? Evidence from four tasks. Society for Neuroscience Abstracts, 19, 363.

Davidson, T. L., McKernan, M. G., \& Jarrard, L. E. (1993). Hippocampal lesions do not impair negative patterning: A challenge to configural association theory. Behavioral Neuroscience, 107, 227234.

Gallagher, M., \& Holland, P. C. (1992). Preserved configural learning and spatial learning impairment in rats with hippocampal damage. Hippocampus, 2, 81-88.

Gulliksen, H., \& WolfLe, D. L. (1938). A theory of learning and transfer. Psychometrika, 3, 127-149.

GLUCK, M. A., \& MYERS, C. E. (1993). Hippocampal mediation of stimulus representation: A computation theory. Hippocampus, $\mathbf{3}$, 491-516.

Mishkin, M., \& Petri, H. L. (1984). Memories and habits: Some implications of the analysis of learning and retention. In L. R. Squire \& N. Butters (Eds.), Neuropsychology of memory (pp. 287-296). New York: Guilford.

Murphy, R. A., McDonald, R. J., Guarraci, F. A., Gortler, J. R., BAKER, A. G., \& White, N. M. (1993). Hippocampal lesions do not impair all forms of configural or contextual learning. Society for Neuroscience Abstracts, 19, 363.

PeArce, J. M. (1987). A model of stimulus generalization for Pavlovian conditioning. Psychological Review, 94, 61-73.

Pearce, J. M., \& Wilson, P. N. (1990). Configural associations in discrimination learning. Journal of Experimental Psychology: Animal Behavior Processes, 16, 250-261.

RazRan, G. H. (1965). Empirical codifications and specific theoretical implications of compound stimulus conditioning: Perception. In W. K. Prokasy (Ed.) Classical conditioning (pp. 226-248). New York: Appleton-Century-Crofts.

Rescorla, R. A. (1972). "Configural" conditioning in discrete-trial bar pressing. Journal of Comparative \& Physiological Psychology, 79, 307-317
ResCorla, R. A., \& WAGNeR, A. W. (1972). A theory of Pavlovian conditioning: Variations in the effectiveness of reinforcement and nonreinforcement. In A. H. Black \& W. F. Prokasy (Eds.), Classical conditioning: 1I. Current research and theory (pp. 63-99). New York: Appleton-Century-Crofts.

RUDY, J. W., \& SUTHERLAND, R. J. (1989). The hippocampus is necessary for rats to learn and remember configural discriminations. $B e$ havioural Brain Research, 34, 97-109.

Rudy, J. W., \& SutherLand, R. J. (1992). Configural and elemental associations and the memory coherence problem. Journal of Cognitive Neuroscience, 4, 208-216.

Rudy, J. W., \& WAGNer, A. R. (1975). Stimulus selection in associative learning. In W. K. Estes (Ed.), Handbook of learning and cognitive processes (Vol. 2, pp. 269-304). Hillsdale, NJ: Erlbaum.

SchmajuK, N. A., \& DiCarLA, J. (1992). Stimulus configuration, classical conditioning and hippocampal function. Psychological Review, 99, 268-305.

SPENCE, K. W. (1936). The nature of discrimination learning. Psychological Review, 43, 427-449.

Sutherland, R. J., Hill, C. R., McDonald, R. J., \& Rudy, J. W. (1989). Damage to the hippocampal formation in rats selectively impairs the ability to learn cue relationships. Behavioral \& Neural Biology, 52, 331-356.

Sutherland, R. J., \& Rudy, J. W. (1989). Configural association theory: The role of the hippocampal formation in learning, memory, and amnesia. Psychobiology, 17, 129-144.

Whishaw, I. Q., \& Tomie, J. (1991). Simple, conditional and configural learning using tactile and olfactory cues is spared in hippocampal rats: Implications for hippocampal function. Behavioral Neuroscience, 105, 787-797.

WHITLOW, J. W., \& WAGNER, A. R. (1972). Negative patterning in classical conditioning: Summation of response tendencies to isolable and configural components. Psychonomic Science, 27, 299-301.

WiCKELGREN, W. A. (1979). Chunking and consolidation: A theoretical synthesis of semantic networks, configuring, $S-R$ versus cognitive learning, normal forgetting, the amnesic syndrome, and the hippocampal arousal system. Psychological Review, 86, 44-60.

WoodBury, C. B. (1943). The learning of stimulus patterns by dogs. Journal of Comparative \& Physiological Psychology, 35, 20-40.

(Manuscript received March 7, 1994; revision accepted for publication January 27,1995 .) 